\title{
Pengaruh Komunitas Pegiat Kota lama Terhadap Perkembangan Vitalitas KaWasan Kota Lama SEMarang
}

\author{
Larasati, Isti Andini, Ana Hardiana \\ Program Studi Perencanaan Wilayah dan Kota, \\ Fakultas Teknik \\ Universitas Sebelas Maret, Surakarta \\ email: ayslaras@gmail.com
}

\begin{abstract}
Semarang old city area is one of the historical district in Indonesia. Semarang old city area was forgotten and abandoned, but it shows progress of condition of its vitality. It is inseparable from the existence of the old city community who has concern the sustainability of the Semarang old town area. The aims of this research are to identify the condition and vitality progress, identify the characteristic of the community and to identify the influence of the community intervention to the area. This research is using quantitative descriptive method supported by analytical techniques such as descriptive analysis to determine the characteristics of community interventions in the area and analysis of simple paired t-test to determine the progression of its vitality. Next, the results of earlier analyzes will be identified by using descriptive explanatory analysis techniques. The results show that Semarang old city area has a significant progress in terms of nine variables vitality assessment indicators. Community intervention in the old city area more on the implementation of the activities and included in the category of active intervention. Therefore, it can be argued that the interventions made by the community influence the progression of the vitality that occur the old city area of Semarang in the last five years, especially in attracting visitors to the old town area of Semarang.
\end{abstract}

Keywords: Vitality area, Semarang Old Town

\section{PENDAHULUAN}

Kawasan Kota Lama Semarang merupakan salah satu kawasan bersejarah di Indonesia. Keistimewaannya terletak pada banyaknya peninggalan bangunan kuno dengan langgam arsitektur klasik sebagai cikal bakal Kota Semarang. Keunikan dan kekhasan fisik dari suatu kawasan bersejarah merupakan hal yang sangat penting untuk dipelihara sebagai bentuk peninggalan yang bernilai sejarah, karena hal tersebut dapat menjadi identitas bagi suatu kawasan (Lynch, 1981).

Permasalahan yang banyak ditemukan dalam pemeliharaan kota-kota lama di Indonesia adalah penurunan vitalitas kawasan yang terjadi karena adanya penurunan kegiatan ekonomi, degradasi lingkungan akibat sarana dan prasarana yang tidak memadai, bangunan tua yang semakin rusak, dan menurunnya nilai lokasi (Wongso, 2007). Vitalitas kawasan merupakan salah satu indikasi penilaian kesehatan kota (Ravenscroft, 2000). Vitalitas dapat diartikan sebagai daya hidup kawasan. Vitalitas kawasan juga sering diasosiasikan dengan kualitas lingkungan dan lebih merujuk kepada kesibukan suatu kota pada lokasi dan waktu yang berbeda. Kawasan kota lama yang hidup dan vital akan mampu mempertahankan eksistensinya. Kawasan tersebut akan memiliki mekanisme pemeliharaan dan kontrol yang langgeng terhadap kualitas lingkungannya melalui pemanfaatan yang produktif (Martokusumo, 2008).

Dalam suatu kawasan kota lama atau kawasan bersejarah, terdapat berbagai faktor yang memengaruhi vitalitas kawasan, salah satunya adalah keberadaan komunitas pada kawasan (Zhou, 2013). Kelompok komunitas yang berperan penting dalam kawasan yang vital mampu secara mandiri untuk melakukan kegiatan atau program baik kegiatan ekonomui mikro maupun kegiatan budaya kolektif. Komunitas bukan saja sebagai suatu subjek dalam pendekatan pembangunan seperti community based development, community driven, community mapping dan yang lainnya, tetapi komunitas sebagai suatu wacana kritis 
terhadap negara, modal dan hasrat (Kusumawijaya, 2014). Komunitas bukan hanya sebagai objek perubahan tapi subjek yang membawa perubahan.

Dalam dua tahun terakhir, upaya menghidupkan kembali kawasan Kota Lama Semarang semakin gencar dilakukan baik oleh pemerintah maupun komunitas. Upaya penyelenggaraan kegiatan banyak dilakukan untuk mengangkat citra kota lama seperti Festival Kota Lama, Semarang Car Free Night, Semarang Kuno Kini Nanti, Symphonie Kota Lama, serta acara tingkat nasional maupun internasional yang diselenggarakan oleh beberapa komunitas. Digelarnya berbagai acara yang menarik di lokasi strategis kota lama menggerakkan masyarakat untuk datang ke kawasan secara sukarela. Dilihat dari antusiasme masyarakat terhadap acara-acara di kota lama, upaya tersebut cukup berhasil untuk menghidupkan kembali Kota Lama Semarang. Tumbuhnya berbagai acara komunitas berbasis sejarah dan budaya beberapa tahun belakangan dapat ditangkap sebagai salah satu potensi yang dapat membangkitkan kembali kehidupan di Kota Lama Semarang. Hal ini menjadi suatu bukti keberadaan komunitas mampu meningkatkan keberadaan kegiatan di Kawasan Kota Lama Semarang.

Mengingat pentingnya kawasan Kota Lama Semarang dan banyaknya intervensi komunitas untuk menghidupkan kembali Kota Lama Semarang, maka diperlukan suatu kajian lebih lanjut mengenai kondisi perkembangan vitalitas kawasan dan pengaruh dari keberadaan komunitas terhadap perkembangan vitalitas kawasan Kota Lama Semarang.

\section{METODE}

\subsection{Ruang Lingkup}

Ruang lingkup wilayah dalam penelitian ini adalah kawasan Kota Lama Semarang dengan sumbu utama kawasan yaitu Jalan Letjen Suprapto, serta batasan yang ditetapkan dalam Rencana Tata Bangunan dan Lingkungan Kota Lama Semarang. Ruang lingkup substansi pada penelitian ini mencakup hal-hal yang berkaitan dengan aspek-aspek vitalitas baik dari segi fisik dan non fisik bagi kawasan perdagangan dan bersejarah serta keterlibatan komunitas sebagai salah satu faktor yang mempengaruhi vitalitas kawasan.

\subsection{Metode Analisis}

Penelitian ini merupakan penelitian deskriptif dengan menggunakan pendekatan deduktif, yaitu penelitian berdasarkan pada teori, kasus, dan studi literatur untuk menguji pertanyaan penelitian yang diturunkan dari teori. Teori terlebih dahulu dijelaskan secara eksplisit untuk kemudian dapat dilanjutkan untuk menguji pertanyaan penelitian.

Pengumpulan data yang dilakukan dalam penelitian ini terbagi menjadi dua yaitu pengumpulan data primer dan sekunder. Pengumpulan data primer dilakukan melalui observasi/pengamatan lapangan, wawancara, dan kuisioner. Pengumpulan data sekunder dilakukan dengan studi literatur.

Analisis yang digunakan dalam penelitian ini terdiri dari tiga tahapan yaitu (1) analisis karakteristik komunitas pegiat kota lama untuk mengetahui karakteristik komunitas dalam keterlibatannya untuk menghidupkan kembali kawasan Kota Lama Semarang dengan teknik analisis deskriptif naratif; (2) analisis perkembangan kondisi vitalitas Kawasan Kota Lama Semarang untuk mengetahui perkembangan vitalitas kawasan yang terjadi pada 9 indikator penilaian vitalitas kawasan yakni aksesibilitas, ketersediaan parkir, ketersediaan unit perdagangan dan jasa, daya tarik kawasan, minat kunjungan ke kawasan, persepsi keamanan, keragaman fungsi, proporsi bangunan kosong, dan lamanya kegiatan pada kawasan. Teknik analisis yang digunakan yaitu analisis skoring, analisis paired sample t-test dan deskriptif naratif; (3) analisis pengaruh intervensi komunitas terhadap perkembangan vitalitas untuk mengetahui bagaimana pengaruh intervensi yang dilakukan oleh komunitas pegiat kota lama terhadap perkembangan vitalitas kawasan Kota Lama Semarang dengan menggunakan teknik analisis deskriptif eksplanatif.

\section{HASIL DAN PEMBAHASAN \\ 3.1 Karakteristik Komunitas Pegiat Kota Lama}

Analisis karakteristik komunitas pegiat kota lama di Kota Lama Semarang dilihat dari beberapa indikator seperti penyelenggaraan kegiatan komunitas pada kawasan, partisipasi masyarakat dalam kegiatan komunitas, penggunaan ruang publik untuk kegiatan komunitas, serta keterlibatan komunitas dalam pengelolaan kawasan.

Pada tahun 2013, beberapa komunitas yang peduli dengan kawasan kota lama membentuk Forum Komunitas Pegiat Kota Lama Semarang. Komunitas-komunitas yang tergabung di dalamnya adalah komunitas Oudestad Art and Culture (OASE), Arsisketur, OrArt-Oret, Jazz Ngisoringin, Semarang Onthel Community, 
Komunitas Klithikan Antik Kota Lama (Koka Kola), dan Lopen Semarang. Forum ini terbentuk karena keresahan anggota komunitas terhadap keberlanjutan kawasan Kota Lama Semarang. Semua komunitas tersebut sepakat untuk mengisi kekosongan dan mengidupkan kegiatan sosial budaya serta atmosfer kota lama dengan kegiatan edukasi kreatif bagi masyarakat. Forum komunitas tersebut masih membuka kesempatan bagi komunitaskomunitas lain yang ingin bergabung untuk menghidupkan kembali kawasan Kota Lama Semarang.

Acara yang diadakan di kawasan kota lama terdiri dari acara tahunan dan acara rutin komunitas. Setiap komunitas memiliki jadwal tertentu untuk berkumpul di Kota Lama Semarang, seperti satu pekan sekali atau satu bulan sekali. Misalnya, komunitas Koka Kola yang mengadakan bazar setiap sebulan sekali di pekan pertama dan Galeri Semarang yang menyajikan atraksi baru setiap dua atau tiga bulan sekali. Berlangsungnya acara-acara komunitas yang terkait dengan Kota Lama Semarang secara tidak langsung telah melibatkan peran aktif masyarakat untuk berperan serta dalam menghidupkan kembali kawasan Kota Lama Semarang.

Daya tarik kota lama semarang yaitu bangunan berarsitektur klasik dan ruang terbuka berupa taman yang dapat dimanfaatkan untuk melakukan kegiatan. Tempat-tempat yang seringkali digunakan sebagai ruang publik di kawasan Kota Lama Semarang yaitu Taman Srigunting dan Taman Garuda-yang beralih fungsi dari taman sebagai pembelah arus di jalan Garuda menjadi ruang publik setelah diselenggarakan Taman Garuda Art Festival oleh komunitas OrArt-Oret pada tahun 2014.

Selain kedua taman tersebut, tempat yang sering digunakan sebagai ruang publik lainnya adalah bangunan eks BTPN (sebelah timur Taman Srigunting) dan Semarang Art Gallery. Bangunan eks BTPN digunakan oleh komunitas Koka Kola sebagai tempat bazar dan Angkringan Blendoek pada malam hari, sedangkan Semarang Art Gallery mulai dapat digunakan oleh publik setelah dikonservasi oleh Chris Darmawan pada tahun 2008. Sebelum digunakan sebagai galeri seni, Semarang Art Gallery merupakan salah satu bangunan tua di kota lama yaitu bangunan bekas pabrik sirup Fres.

Pengelolaan kawasan dan kegiatan di kawasan Kota Lama Semarang dilaksanakan oleh Badan Pengelola Kawasan Kota Lama
(BPK2L). Komunitas pegiat kota lama berperan sebagai pemberi masukan atau aspirasi ke pengelola kawasan.

Intervensi yang dilakukan oleh komunitaskomunitas dalam menghidupkan kembali kawasan Kota Lama Semarang lebih banyak dilakukan dengan mengadakan kegiatankegiatan yang bertujuan untuk mengundang pengunjung datang ke kawasan. Kegiatan yang diselenggarakan di kawasan kota lama mencerminkan kehidupan yang terjadi di kawasan Kota Lama Semarang.

Kegiatan yang pertama kali diselenggarakan adalah Festival Kota Lama Semarang. Acara yang rutin diadakan setiap tahun ini secara tidak langsung mempromosikan kawasan Kota Lama Semarang dan menarik perhatian pengunjung serta komunitas-komunitas lain untuk beraktivitas di kawasan Kota Lama Semarang. Keberadaan komunitas pegiat kota lama Semarang secara tidak langsung mempengaruhi kondisi indikator-indikator vitalitas kawasan.

\subsection{Perkembangan Kondisi Vitalitas Kawasan Kota Lama Semarang}

Perkembangan vitalitas kawasan Kota Lama Semarang dilihat dari sembilan aspek penilaian vitalitas yaitu aksesibilitas, ketersediaan parkir, ketersediaan perdagangan dan jasa, daya tarik kawasan, minat kunjungan ke kawasan, persepsi keamanan, keragaman fungsi bangunan, proporsi bangunan kosong, serta lama kegiatan pada kawasan. Berdasarkan hasil analisis paired sample t-test dan analisis deskriptif naratif tentang perkembangan vitalitas kawasan, berikut ini merupakan kondisi perkembangan vitalitas kawasan Kota Lama Semarang.

Tabel 1. Perkembangan Vitalitas Kawasan Kota Lama Semarang

\begin{tabular}{|l|l|}
\hline \multicolumn{1}{|c|}{ Variabel } & \multicolumn{1}{c|}{ Hasil } \\
\hline \multirow{5}{*}{ Aksesibilitas } & $\begin{array}{l}\text { Hasil paired } \text {-test menunjukkan adanya } \\
\text { perubahan pada aksesibilitas kawasan } \\
\text { sebelum dan sesudah adanya intervensi } \\
\text { komunitas pada kawasan. Hasil skoring } \\
\text { menunjukkan perubahan sebesar 14 } \\
\text { poin. Terdapat penambahan moda } \\
\text { transportasi umum Bus Rapid Transit }\end{array}$ \\
& Semarang \\
\hline \multirow{5}{*}{$\begin{array}{l}\text { Ketersediaan } \\
\text { parkir }\end{array}$} & $\begin{array}{l}\text { Hasil analisis paired t-test } \\
\text { menunjukkan adanya perubahan pada } \\
\text { kondisi ketersediaan parkir di kawasan } \\
\text { sebelum dan sesudah adanya intervensi } \\
\text { komunitas. Perubahan sebesar 38 poin. } \\
\text { Kawasan belum memiliki area parkir } \\
\text { khusus, masih menggunakan parkir } \text { on } \\
\text { street }\end{array}$ \\
\hline
\end{tabular}




\begin{tabular}{|c|c|}
\hline Variabel & Hasil \\
\hline $\begin{array}{l}\text { Daya tarik } \\
\text { kawasan }\end{array}$ & $\begin{array}{l}\text { Dari hasil analisis paired t-test, Sig } \\
\text { menunjukkan angka } 0,038 \text {. Dapat } \\
\text { dikatakan bahwa daya tarik kawasan } \\
\text { sebelum dan sesudah adanya intervensi } \\
\text { komunitas mengalami perubahan. } \\
\text { Perubahan sebesar } 44 \text { poin. Tidak } \\
\text { hanya bangunan tua, kegiatan yang } \\
\text { diselenggarakan oleh komunitas } \\
\text { menjadi daya tarik baru pada kawasan }\end{array}$ \\
\hline $\begin{array}{l}\text { Minat } \\
\text { kunjungan } \\
\text { ke kawasan }\end{array}$ & $\begin{array}{l}\text { Hasil paired t-test menunjukkan adanya } \\
\text { perubahan pada minat kunjungan ke } \\
\text { kawasan sebelum dan sesudah adanya } \\
\text { intervensi komunitas. Hasil skoring } \\
\text { menunjukkan perubahan sebesar } 72 \\
\text { poin. Menurut responden, minat } \\
\text { kunjungan ke Kota Lama Semarang } \\
\text { mengalami peningkatan. }\end{array}$ \\
\hline $\begin{array}{l}\text { Ketersediaan } \\
\text { Perdagangan } \\
\text { dan Jasa }\end{array}$ & $\begin{array}{l}\text { Dari hasil analisis paired - test, Sig } \\
\text { menunjukkan angka } 0,002 \text {. Dapat } \\
\text { dikatakan bahwa ketersediaan kegiatan } \\
\text { perdagangan dan jasa untuk melayani } \\
\text { kawasan mengalami perubahan } \\
\text { sebelum dan sesudah terdapat intervensi } \\
\text { komunitas. }\end{array}$ \\
\hline $\begin{array}{l}\text { Persepsi } \\
\text { Keamanan }\end{array}$ & $\begin{array}{l}\text { Dari hasil analisis paired t test, Sig } \\
\text { menunjukkan angka } 0,007 \text {. Dapat } \\
\text { dikatakan bahwa persepsi masyarakat } \\
\text { mengenai keamanan kawasan } \\
\text { mengalami perubahan sebelum dan } \\
\text { sesudah terdapat intervensi komunitas. } \\
\text { Sebagian besar responden merasa aman } \\
\text { untuk berkunjung ke kawasan. }\end{array}$ \\
\hline $\begin{array}{l}\text { Keragaman } \\
\text { fungsi ruang }\end{array}$ & $\begin{array}{l}\text { Tidak terdapat penambahan jenis fungsi } \\
\text { ruang, perubahan hanya terjadi pada } \\
\text { jumlah bangunan yang digunakan untuk } \\
\text { kegiatan. }\end{array}$ \\
\hline $\begin{array}{l}\text { Proporsi } \\
\text { bangunan } \\
\text { kosong }\end{array}$ & $\begin{array}{l}\text { Terdapat perubahan jumlah bangunan } \\
\text { kosong ( } 24 \text { bangunan) pada kawasan } \\
\text { yang digunakan untuk kegiatan } \\
\text { perdagangan dan jasa serta perkantoran. }\end{array}$ \\
\hline $\begin{array}{l}\text { Lama } \\
\text { kegiatan }\end{array}$ & $\begin{array}{l}\text { Tidak terdapat perubahan operasional } \\
\text { lama kegiatan, namun terdapat kegiatan } \\
\text { yang mulai beroperasi dari siang hingga } \\
\text { malam hari. }\end{array}$ \\
\hline
\end{tabular}

Perubahan terjadi pada 8 indikator vitalitas kawasan di antaranya aksesibilitas, ketersediaan parkir, ketersediaan perdagangan dan jasa, proporsi bangunan kosong, lama kegiatan pada kawasan, minat kunjungan ke kawasan serta persepsi keamanan. Perubahan yang terjadi dalam kurun waktu 2010-2015 berada pada kategori berubah signifikan.

\subsection{Pengaruh Intervensi Komunitas terhadap Kondisi Vitalitas Kawasan Kota Lama Semarang}

Delapan indikator penilaian kondisi vitalitas kawasan mengalami perubahan karena adanya intervensi yang dilakukan oleh komunitas. Perubahan tersebut merupakan perubahan kondisi yang lebih baik untuk semua indikator vitalitas Kawasan Kota Lama Semarang dari sebelum dan sesudah keberadaan komunitas. Perkembangan yang terjadi hanya pada sebagian indikator vitalitas kawasan karena intervensi yang dilakukan komunitas hanya berfokus untuk mengisi kekosongan kegiatan pada kawasan.

Intervensi yang dilakukan komunitas dikatakan cukup aktif dalam 5 tahun terakhir terutama pada penyelenggaraan kegiatan di ruang publik kawasan dan mengajak serta masyarakat sekitar untuk berpartisipasi meningkatkan vitalitas Kawasan Kota Lama Semarang.

Berdasarkan hasil analisis, terlihat bahwa keberadaan komunitas di Kawasan Kota Lama Semarang merupakan salah satu faktor yang dapat meningkatkan vitalitas Kawasan Kota Lama Semarang seperti yang disampaikan oleh beberapa teori dari Tyler (1998), Zielenbach (2002), dan Zhou (2013) yang mengatakan bahwa people yang dalam hal ini dianggap sebagai komunitas merupakan salah satu elemen penting pada suatu kawasan yang memengaruhi vitalitas kawasan kota selain place (ruang kawasan) dan program (kegiatan). Intervensi kegiatan yang dilakukan oleh masyarakat secara sukarela merupakan salah satu upaya yang dapat dilakukan untuk meningkatkan daya hidup Kawasan Kota Lama Semarang sebagai pusat kegiatan di Kota Semarang.

\section{KESIMPULAN}

Hasil penelitian menunjukkan bahwa intervensi yang dilakukan oleh komunitas pegiat kota lama turut memengaruhi perkembangan vitalitas kawasan Kota Lama Semarang. Indikator vitalitas yang dipengaruhi antara lain daya tarik kawasan, minat kunjungan ke kawasan, ketersedian parkir, ketersediaan perdagangan dan jasa, proporsi bangunan kosong, lama kegiatan pada kawasan serta persepsi keamanan. Perkembangan yang paling signifikan adalah jumlah pengunjung yang tertarik untuk datang ke kawasan. Kegiatan yang diselenggarakan oleh komunitas pada kawasan menarik pengunjung untuk datang ke kawasan Kota Lama Semarang. Indikator lain yang mengalami perubahan seperti aksesibilitas dan keragaman fungsi kawasan tidak dipengaruhi oleh intervensi komunitas melainkan dipengaruhi pengelolaan kawasan oleh BPK2L. 


\section{REFERENSI}

Kusumawijaya, Marco. (2014). Komunitas sebagai Kritik Terhadap Negara Modal, dan Hasrat (Bahan diskusi untuk Urban Social Forum Surakarta). Diperoleh 11 Januari 2016 dari https://mkusumawijaya .wordpress.com/2014/12/17/komunitassebagai-kritik-terhadap-negara-modaldan-hasrat1

Lynch, K. (1981). Good City Form.

Massachusetts: The MIT Press.

Martokusumo. (2008, Desember). Revitalisasi sebuah pendekatan dalam peremajaan kawasan . Jurnal PWK ITB Vol 19 No.3.

Ravenscroft, N. (2000). The Vitality and Viability of Town Centres. Urban Studies, Vol. 37, 2533-2549.

Tyler, N. (1998). Evaluating the Health of Downtown. Wisconsin: Center for Community Economic Development.

Wongso, J. (2007). Strategi Revitalisasi Pusat Kota Bukit Tinggi. Universitas Bung Hatta.

Zielenbach, S. (2002). The Art of Revitalization: Improving Conditions in distressed inner-city neigborhoods. New York: Garland Publishing Inc.

Zhou, J. (2012). Urban Vitality on Dutch and Chinese New Town. Delft: ABE TU Delft. 


\section{LAMPIRAN}

Lampiran 1 Tabel Hubungan Jalan Lingkar dengan Perkembangan Wilayah

\begin{tabular}{|c|c|c|}
\hline $\begin{array}{l}\text { Perkembangan } \\
\text { Warakteristik } \\
\text { Jalan }\end{array}$ & $\begin{array}{c}\text { Stagnan/ Berkembang tidak } \\
\text { signifikan }\end{array}$ & Berkembang signifikan \\
\hline Intervensi aktif & $\begin{array}{c}\text { Hubungan A } \\
\text { Intervensi aktif komunitas pada } \\
\text { kawasan, namun vitalitas kawasan } \\
\text { kawasan stagnan/berkembang } \\
\text { tidak signifikan. Hal ini } \\
\text { menandakan bahwa intervensi } \\
\text { yang dilakukan komunitas pada } \\
\text { kawasan tidak berpengaruh } \\
\text { terhadap perkembangan vitalitas } \\
\text { kawasan. }\end{array}$ & $\begin{array}{c}\text { Hubungan B } \\
\text { Intervensi aktif komunitas pada } \\
\text { kawasan dan vitalitas kawasan } \\
\text { berkembang signifikan. Hal ini } \\
\text { menandakan bahwa intervensi yang } \\
\text { dilakukan komunitas pada kawasan } \\
\text { memberi berpengaruh terhadap } \\
\text { perkembangan vitalitas kawasan. }\end{array}$ \\
\hline Intervensi pasif & $\begin{array}{c}\text { Hubungan C } \\
\text { Intervensi pasif komunitas pada } \\
\text { kawasan dan vitalitas kawasan } \\
\text { kawasan stagnan/berkembang } \\
\text { tidak signifikan. Hal ini } \\
\text { menandakan bahwa intervensi } \\
\text { yang pasif pada kawasan } \\
\text { mempengaruhi perkembangan } \\
\text { vitalitas kawasan }\end{array}$ & $\begin{array}{c}\text { Hubungan D } \\
\text { Intervensi pasif komunitas pada } \\
\text { kawasan namun, vitalitas kawasan } \\
\text { berkembang signifikan. Hal ini } \\
\text { menandakan bahwa perkembangan } \\
\text { vitalitas kawasan yang terjadi bukan } \\
\text { dipengaruhi oleh intervensi } \\
\text { komunitas, melainkan oleh faktor } \\
\text { lain. }\end{array}$ \\
\hline
\end{tabular}

